\title{
Chromosome studies in investigation of stillbirths and neonatal deaths ${ }^{\star}$
}

\author{
RHONA BAULD, GRANT R. SUTHERLAND, and A. DOUGLAS BAIN \\ From the Department of Pathology, Royal Hospital for Sick Children, Edinburgh, and the University of \\ Edinburgh
}

\begin{abstract}
Bauld, R., Sutherland, G. R., and Bain, A. D. (1974). Archives of Disease in Childhood, 49, 782. Chromosome studies in investigation of stillbirths and neonatal deaths. Chromosome studies have been attempted on all late abortions, stillbirths, and neonates coming to necropsy in Edinburgh over a 1-year period. Results were obtained in 153 cases and of these $7 \cdot 2 \%$ had chromosome abnormalities. It is suggested that chromosome studies should become a routine part of the perinatal necropsy.
\end{abstract}

With the decrease in perinatal mortality in recent years the genetic component in this problem has assumed increasing significance. There is only one report of cytogenetic studies having been carried out on a consecutive series of perinatal deaths (Machin, 1974). Chromosome abnormalities in such a population were found to be 10 times more frequent than in unselected liveborn infants. Over a period of one year ending on 30 September 1973, chromosome studies were carried out on all late abortions, stillbirths, and neonates coming to necropsy in this department.

\section{Materials and methods}

All routine necropsies on late abortions, stillbirths, and neonatal deaths in the Edinburgh area are carried out in this department. For the purpose of this study they were categorized as follows.

Abortions: fetuses of more than 20 but of less than 28 weeks' gestation.

Perinatal deaths: stillbirths of more than 28 weeks' gestation and all liveborn infants who have not lived for more than one week, regardless of gestation. These were further divided in 3 groups, macerated stillbirths, nonmacerated stillbirths, and early neonatal deaths.

Older neonates: those who lived for more than one week but for less than 28 days.

Where possible, chromosome studies were carried out

Received 20 February 1974.

*Based on a paper presented to the 19th Annual Meeting of the Paediatric Pathology Society, Glasgow, October 1973. on all such cases; three techniques were used. (1) Heart blood lymphocyte culture which was attempted only in the case of liveborn infants who had been dead for less than 8 hours. (2) Spleen lymphocyte culture in the presence of phytohaemagglutinin using the method of Bain and Gauld (1964). (3) Fibroblast culture for which a variety of tissues are suitable. In this survey gonad and pericardium were the main tissues used. Towards the end of the survey fibroblast culture of placental amnion from macerated stillbirths was attempted (Machin, 1974). The tissue was collected aseptically at necropsy, placed in a sterile vial containing culture medium, and transported to the laboratory. Explants of tissue were set up in glass culture bottles using a chicken-plasma clot technique. After these primary cultures had been subcultured, chromosome results were obtained using standard methods. A minimum of 10 cells per case were analysed and then checked by an independent observer; a karyotype was prepared. When chromosome banding was required the technique of Grace and Bain (1972) was employed.

\section{Results}

During this survey there were 242 consecutive necropsies in the categories selected for chromosome studies. Chromosome studies were not attempted on 42 macerated stillbirths in the early part of the survey, nor in 16 other instances for a variety of reasons (such as severe pyogenic infection).

The chromosome findings according to category are shown in Table I. A high percentage of chromosome abnormalities were found among the abortions and macerated stillbirths, but the numbers were too small to attach significance to these findings. The figures for perinatal deaths are more 
TABLE I

Chromosome results by category

\begin{tabular}{|c|c|c|c|c|c|c|}
\hline \multirow{2}{*}{ Status } & \multirow{2}{*}{ Total no. of necropsies } & \multirow{2}{*}{$\begin{array}{l}\text { Chromosome studies } \\
\text { attempted }\end{array}$} & \multicolumn{2}{|c|}{ Results } & \multicolumn{2}{|c|}{ Abnormal karyotypes } \\
\hline & & & No. & $\%$ & No. & $\%$ \\
\hline $\begin{array}{l}\text { Abortion } \\
\text { Macerated stillbirths } \\
\text { Nonmacerated stillbirths } \\
\text { Early neonatal deaths } \\
\text { Older neonates }\end{array}$ & $\begin{array}{r}9 \\
52 \\
47 \\
114 \\
20\end{array}$ & $\begin{array}{r}5 \\
14 \\
39 \\
108 \\
18\end{array}$ & $\begin{array}{r}5 \\
3 \\
32 \\
98 \\
15\end{array}$ & $\begin{array}{r}100 \\
21 \\
82 \\
91 \\
83\end{array}$ & $\begin{array}{r}2 \\
1 \\
1 \\
7 \\
-\end{array}$ & $\begin{array}{l}40 \\
33 \\
3 \cdot 1 \\
7 \cdot 1 \\
-\end{array}$ \\
\hline Total & 242 & 184 & 153 & 83 & 11 & $7 \cdot 2$ \\
\hline
\end{tabular}

representative of the incidence of chromosome abnormalities in the population studied since the numbers are larger. It is interesting to note that no chromosome abnormalities were found in the 'older neonates'.

The tissues from which chromosome results were obtained are listed in Table II. A number of the

TABLE II

Tissue from which results were obtained

\begin{tabular}{l|c|c}
\hline \multicolumn{1}{c|}{ Tissue } & No. attempted & No. successful \\
\hline Blood (during life) & 10 & 10 \\
Heart blood & 2 & 2 \\
Spleen & 102 & 27 \\
Other tissue & 145 & 114 \\
(fibroblast cultures) & & \\
\hline
\end{tabular}

results were obtained from blood lymphocyte culture established before death. The number of heart blood samples used in the study was small because of the time delay between death and necropsy, which was usually greater than 8 hours, generally about 2 days, and occasionally up to 5 days. Approximately one-quarter of the spleen samples yielded chromosome results. When results were obtained from these tissues, the slower fibroblast cultures were discarded. Of the 145 cases where fibroblast cultures were continued there were 31 cases where chromosome results were not obtained. This was due to bacterial contamination in 7 cases, and to primary growth failure in 24 cases. In 11 of these 24 cases the tissue was from macerated fetuses and growth failure was not unexpected. In these fetuses all the cells are dead, but placental amnion may contain viable cells which are suitable for fibroblast culture. In 13 cases there was no apparent reason for the growth failure.

The chromosome results according to primary necropsy findings are shown in Table III. The overall incidence of chromosome anomalies was $7 \%$.
TABLE III

Chromosome results in relation to primary necropsy findings

\begin{tabular}{|c|c|c|c|c|}
\hline \multirow{2}{*}{$\begin{array}{l}\text { Primary necropsy } \\
\text { findings }\end{array}$} & \multirow{2}{*}{ No. } & \multirow{2}{*}{$\begin{array}{c}\text { Chromosome } \\
\text { results } \\
\text { obtained }\end{array}$} & \multicolumn{2}{|c|}{$\begin{array}{l}\text { Abnormal } \\
\text { karyotypes }\end{array}$} \\
\hline & & & No. & $\%$ \\
\hline $\begin{array}{l}\text { Abortion } \\
\text { Macerated fetus } \\
\text { without congenital } \\
\text { malformations } \\
\text { Prematurity associated } \\
\text { disease } \\
\text { Primary CNS } \\
\text { abnormality } \\
\text { Multiple congenital } \\
\text { abnormalities } \\
\text { Primary anoxia } \\
\text { Infection } \\
\text { Miscellaneous }\end{array}$ & $\begin{array}{r}44 \\
60 \\
43 \\
\\
42 \\
35 \\
5 \\
4\end{array}$ & $\begin{array}{r}2 \\
53 \\
29 \\
\\
32 \\
26 \\
4 \\
2\end{array}$ & $\begin{array}{c}- \\
- \\
6 \\
1 \\
1 \\
-\end{array}$ & $\begin{array}{c}- \\
1.9 \\
- \\
18.8 \\
3.8 \\
25.0 \\
-\end{array}$ \\
\hline Total & 242 & 153 & 11 & $7 \cdot 2$ \\
\hline
\end{tabular}

Of 61 cases with severe congenital malformations there were 6 with chromosome abnormalities, an incidence of $10 \%$. Of the remaining 91 cases without significant congenital malformations $4(4 \%)$ had chromosome abnormalities. Except for the cases of Edwards's syndrome and the unbalanced translocation, the other chromosome abnormalities were not suspected either clinically or at necropsy. This includes the case of Down's syndrome, an infant of 26 weeks' gestation where the extra chromosome was identified as number 21 using G-banding. Details of the cytogenetics of the 11 abnormal cases are listed in Table IV. In all cases analysis of $\mathbf{4 0}$ cells was attempted in order to rule out mosaicism, but this was considered unlikely in Case 479 , where the unbalanced karyotype was of paternal derivation, and only 25 cells were examined. When non-modal cells were observed the loss of chromosomes appeared to be random. Failure to examine $\mathbf{4 0}$ cells in other cases was due to loss of the cell strain; this was also one reason for not 
TABLE IV

Cytogenetic findings in the cases with abnormal karyotypes

\begin{tabular}{|c|c|c|c|c|c|c|c|c|}
\hline \multirow{2}{*}{ Case no. } & \multirow{2}{*}{ Category } & \multirow{2}{*}{ Karyotype } & \multirow{2}{*}{ Tissue } & \multicolumn{5}{|c|}{ Chromosome counts } \\
\hline & & & & 45 & 46 & 47 & $3 N$ & Total \\
\hline $\begin{array}{l}246 \\
218 \\
472 \\
351 \\
387 \\
419 \\
264 \\
479 \\
461 \\
294 \\
297\end{array}$ & $\begin{array}{l}\text { Early neonatal death } \\
\text { Macerated stillbirth } \\
\text { Early neonatal death } \\
\text { ", } \\
\text { Nonmacerated stillbirth } \\
\text { Early neonatal death } \\
\text { Abortion" } \\
\text {," }\end{array}$ & $\begin{array}{l}47, X X,+21 \\
47, X Y,+18 \\
47, X Y,+18 \\
47, X X,+18 \\
47, X X,+18 \\
47, X X,+18 \\
47, X X X \\
46, X Y, \text { der } 13, t(7 ; 13)(q 36 ; \text { q22) pat. } \\
46, X X / 47, X X,+C \\
46, X Y / 47, X Y,+C \\
69, X X Y\end{array}$ & $\begin{array}{l}\text { Spleen } \\
\text { Fibroblast } \\
\text { Fibroblast (amnion) } \\
\text { Spleen } \\
\text { Blood } \\
\text { Fibroblast } \\
\text { Fibroblast } \\
\text { Heart blood } \\
\text { Fibroblast } \\
\text { Fibroblast } \\
\text { Fibroblast }\end{array}$ & 2 & $\begin{array}{r}3 \\
2 \\
1 \\
2 \\
5 \\
25 \\
28 \\
49\end{array}$ & $\begin{array}{r}45 \\
40 \\
9 \\
39 \\
38 \\
34 \\
35 \\
\\
4 \\
6\end{array}$ & 50 & $\begin{array}{l}50 \\
40 \\
11 \\
40 \\
40 \\
40 \\
35 \\
25 \\
32 \\
55 \\
50\end{array}$ \\
\hline
\end{tabular}

TABLE V

Seasonal incidence of chromosome abnormalities

\begin{tabular}{|c|c|c|c|c|c|c|c|c|c|c|c|c|}
\hline & Oct & Nov & Dec & Jan & Feb & Mar & Apr & May & June & July & Aug & Sept \\
\hline $\begin{array}{l}\text { Chromosome results } \\
\text { Chromosome } \\
\text { abnormalities } \\
\text { Trisomy } 18\end{array}$ & 9 & $\begin{array}{r}11 \\
1 \\
1\end{array}$ & $\begin{array}{r}17 \\
1\end{array}$ & $\begin{array}{c}12 \\
1\end{array}$ & $\begin{array}{l}8 \\
1\end{array}$ & $\begin{array}{r}12 \\
1\end{array}$ & $\begin{array}{r}16 \\
1 \\
1\end{array}$ & $\begin{array}{r}13 \\
1 \\
1\end{array}$ & 13 & $\begin{array}{r}15 \\
1 \\
1\end{array}$ & 10 & $\begin{array}{r}16 \\
3 \\
1\end{array}$ \\
\hline
\end{tabular}

identifying the extra $\mathrm{C}$ group chromosomes in the two mosaics. Studies of histological sections of Case 461 showed some cells which appeared to have two sex chromatin bodies. Similar studies of Case 294 showed no evidence of sex chromatin.

The seasonal incidence of the birth of chromosomally abnormal cases is shown in Table V. These appear to be randomly distributed overall, but there does seem to be some clustering of the $E$ trisomies.

The cases of chromosome abnormality were not uniformly distributed with respect to maternal age, as can be seen from Table VI, a higher proportion being born to older mothers. The ages of 11 mothers were not ascertained and these were

\section{TABLE VI}

Distribution of cases with chromosome abnormalities according to the age of the mother

\begin{tabular}{|c|c|c|c|c|c|c|}
\hline & \multicolumn{6}{|c|}{ Age intervals (yr) } \\
\hline & $<20$ & $20-24$ & $25-29$ & $30-34$ & $35-39$ & $\geqslant 40$ \\
\hline $\begin{array}{l}\text { All karyotyped } \\
\text { infants } \\
\text { Chromosomally } \\
\text { abnormal } \\
\text { Abnormal } \\
\text { karyotype (\%) }\end{array}$ & $\begin{array}{l}12 \\
-\end{array}$ & $\begin{array}{l}59 \\
3 \\
5 \cdot 1\end{array}$ & $\begin{array}{l}51 \\
4 \\
7 \cdot 8\end{array}$ & $\begin{array}{l}17 \\
1 \\
5 \cdot 9\end{array}$ & $\begin{array}{c}9 \\
1 \\
11 \cdot 1\end{array}$ & $\begin{array}{r}5 \\
2 \\
40\end{array}$ \\
\hline
\end{tabular}

distributed proportionately into the various age groups.

\section{Discussion}

The only reported study comparable to the present one is that of Machin (1974) who karyotyped 500 unselected perinatal deaths in the London area over a 3-year period. This series is compared with the present one in Table VII. The findings in the two series are in close agreement, especially if the two categories, abortions and older neonates, not studied by Machin (1974) are excluded. The incidence of chromosome abnormality in the Edinburgh survey would then be $6 \cdot 8 \%$ compared with $5.6 \%$ for the comparable data from London. The incidence of $7 \cdot 2 \%$ of chromosome abnormality in the present series is 10 times higher than the incidence of $0.71 \%$ of chromosome abnormalities detected in a series of 11,000 unselected liveborn infants also studied in Edinburgh (Ratcliffe and Keay, 1973). Hence, the only two series of chromosome studies on perinatal deaths agree that there is an excess of infants with chromosome abnormalities dying in this period.

The types of chromosome abnormality detected in perinatal deaths are compatible with survival beyond birth and are not generally of the type usually seen in early abortions (Hamerton, 1971). In both series the most frequently encountered chromosome 
TABLE VII

Comparison of the results of two chromosome surveys carried out on infants dying in the perinatal period

\begin{tabular}{|c|c|c|c|c|}
\hline \multirow{3}{*}{ Category } & \multicolumn{4}{|c|}{ Series } \\
\hline & \multicolumn{2}{|c|}{ Machin (1974), London } & \multicolumn{2}{|c|}{ This study, Edinburgh } \\
\hline & No. karyotyped & $\%$ abnormal & No. karyotyped & $\%$ abnormal \\
\hline $\begin{array}{l}\text { Late abortion } \\
\text { Macerated stillbirth } \\
\text { Nonmacerated stillbirths } \\
\text { Early neonatal deaths } \\
\text { Older neonates }\end{array}$ & $\begin{array}{r}- \\
34 \\
122 \\
344 \\
-\end{array}$ & $\begin{array}{l}- \\
8 \cdot 8 \\
4 \cdot 1 \\
5 \cdot 8 \\
-\end{array}$ & $\begin{array}{r}5 \\
3 \\
32 \\
98 \\
15\end{array}$ & $\begin{array}{l}40 \\
33 \\
3 \cdot 1 \\
7 \cdot 1 \\
0\end{array}$ \\
\hline Total & 500 & $5 \cdot 6$ & 153 & $7 \cdot 2$ \\
\hline
\end{tabular}

abnormality was trisomy 18 . In the series of Machin (1974) 8 out of 28 infants with chromosome abnormality had trisomy 18 , and in the present series this abnormality accounted for 5 of the 11 cases found. Hence, the present findings support the contention (Bain, 1973; Machin, 1974) that trisomy 18 may be more common than was originally estimated by Taylor (1968).

As would be expected, most of the chromosome abnormalities were associated with congenital malformations. If the severe congenital malformations were subdivided according to whether or not they were primarily of the CNS (anencephaly, spina bifida, encephalocele, etc.), it is seen that while the overall chromosome abnormality rate in congenital malformations is $10.2 \%$ these were confined exclusively to those cases in which the malformations did not primarily involve the CNS, and in this group the incidence of chromosome abnormality was $18.9 \%$. Machin (1974) did not divide his congenital malformations in this manner, but found that $13 \%$ of this whole group had a chromosome abnormality.

In those without recognizable malformations there were $4.4 \%$ with a chromosome abnormality and these are of particular interest since they were unsuspected and would have gone undetected but for this survey. Machin (1974) found that $2.5 \%$ of his cases without malformations had a chromosome abnormality. Hence, even in perinatal deaths where there is no congenital malformation, the incidence of chromosome abnormality is about 5 times greater than that in unselected liveborn infants.

Seasonal clustering of the chromosome abnormalities was not apparent in the present series as a whole, but 4 of the 5 cases of trisomy 18 were found in the period from April to September. This corresponds with the findings of Machin (1974) whose 8 cases with this abnormality occurred between March and July. Taylor (1968) found that there was a clustering of both $\mathrm{D}$ and $\mathrm{E}$ trisomic infants in the period from June to November. All these periods of increased incidence of trisomy 18 overlap, but they do indicate that this anomaly is less likely to occur in the winter months than at other times of the year. Others have reported seasonal variations in the incidence of chromosome abnormalities (e.g. Robinson et al., 1969; Jongbloet, 1970; Nielsen, Petersen, and Therkelsen, 1973), but little data from chromosome surveys of unselected neonates has been analysed in this manner.

The increase in the incidence of chromosome abnormalities with maternal age is well recognized; nevertheless, the relation between maternal age and chromosome abnormality in the two series of studies on perinatal deaths is striking. The stillbirths and neonatal deaths from mothers younger than 20 years had about a $1 \%$ chance of having a chromosome abnormality, yet those from mothers older than $\mathbf{4 0}$ years had a 30 to $40 \%$ chance of having such an abnormality. Mothers in this latter group should routinely be offered antenatal diagnosis of chromosome abnormalities (Sutherland, 1972; Bain and Sutherland, 1973).

The techniques for obtaining chromosome results at post mortem have lower success rates than similar studies during life. Obtaining results from macerated fetuses is particularly difficult, though amnion culture (Machin, 1974), which was only attempted towards the end of the present series, has produced results on occasions when other cultures have failed. This is obviously the method of choice for such fetuses and it is anticipated that in future chromosome results will be obtained from a proportion of these. When suitable tissue is available from nonmacerated stillbirths or from neonates then success rates in the vicinity of $90 \%$ should be attained. The elimination of microbial contamination of cultures could increase the success 
rate, but this still leaves a number of cases of unexplained primary growth failure.

Hence it has been shown, in two different centres, that chromosome abnormalities are present in 5 to $10 \%$ of perinatal deaths. In view of this it is suggested that chromosome studies should become an integral part of the perinatal necropsy. Chromosome results from dead neonates are particularly valuable when counselling parents. A normal result suggests that the chances of recurrence should be sought from the other pathological findings and an abnormal result indicates that amniocentesis in subsequent pregnancies should be strongly considered.

Some necropsies in this series were carried out by Dr. J. M. Anderson. We thank Mrs. Elizabeth Grace and Mrs. Susan Bowser-Reilly for help with cytogenetic studies, and Mrs. Eleanor Cochrane and Miss Dorothy Seymour for help with the tissue culture.

We thank the M.R.C. Clinical and Population Cytogenetics Unit for allowing us to use their results on some of the infants studied while alive. This work was supported in part by the Distillers Co. Ltd. grant to the University of Edinburgh.

\section{REFERENCES}

Bain, A. D. (1973). Chromosomal abnormalities. In Textbook of Paediatrics. Ed. by J. O. Forfar and G. C. Arneil. Churchill Livingstone, Edinburgh and London.

Bain, A. D., and Gauld, I. K. (1964). The use of thymus and spleen in the demonstration of chromosomes postmortem in foetuses and infants. British fournal of Experimental Pathology, 45, 530.

Bain, A. D., and Sutherland, G. R. (1973). Antenatal screening for Down's syndrome. Lancet, 1, 423.

Grace, E., and Bain, A. D. (1972). A simple method for chromosome banding. Fournal of Clinical Pathology, 25, 910.

Hamerton, J. L. (1971). Human Cytogenetics, Vol. 2. Academic Press, London and New York.

Jongbloet, P. H. (1970). Chromosomal aberrations and month of birth. Lancet, 2, 1317.

Machin, G. A. (1974). Chromosome abnormality and perinatal death. Lancet, 1, 549.

Nielsen, J., Petersen, G. B., and Therkelsen, A. J. (1973). Seasonal variation in the birth of children with aneuploid chromosome abnormalities. Report from the Danish Cytogenetic Central Register. Humangenetik, 19, 67.

Ratcliffe, S. G., and Keay, A. J. (1973). Chromosome studies on 11,000 newborn infants. Archives of Disease in Childhood, 48, 407.

Robinson, A., Goad, W. B., Puck, T. T., and Harris, J. S. (1969). Studies on chromosomal nondisjunction in man. III. American fournal of Human Genetics, 21, 466.

Sutherland, G. R. (1972). The role of amniocentesis in genetic counselling. Australian fournal of Mental Retardation, 2, 85.

Taylor, A. I. (1968). Autosomal trisomy syndromes: a detailed study of 27 cases of Edwards' syndrome and 27 cases of Patau's syndrome. Fournal of Medical Genetics, 5, 227.

Correspondence to Mrs. R. Bauld, Department of Pathology, Royal Hospital for Sick Children, Edinburgh EH9 1LF.

\section{Appendix}

This appendix consists of the main pathological findings in the 11 cases with chromosome abnormalities listed in Table IV in the text.

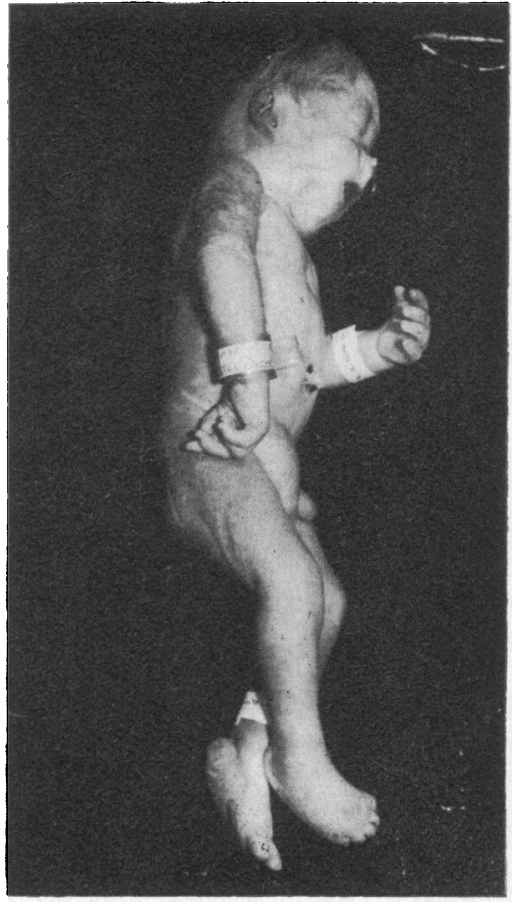

FIG. 1.-Case 218. Note abnormal ears, flexion deformity of right fingers, short great toes, rocker-bottom feet.

Case 246. Karyotype $47, \mathrm{XX},+21$; age $1 \frac{\mathrm{hr}}{}$ gestation 26 weeks; weight at necropsy $1335 \mathrm{~g}$. No recognizable malformations; gross ascites and subcutaneous oedema confined to the trunk. Brain and meninges normal. Heart normal. Small intestine was narrow indicating ascites had been present for some time.

Case 218. Karyotype $47, \mathrm{XY},+18$; age $31 \mathrm{hr}$; gestation 38 weeks; weight at necropsy $1880 \mathrm{~g}$. External features were in keeping with a chromosome abnormality but not typical of trisomy 18. Ears abnormal. Unilateral flexion deformities of the fingers; right talipes equinovarus; left foot had a rocker-bottom appearance; great toes short. Single umbilical artery. No Simian creases. Head: anterior falx cerebri defect, adhesion of cerebral hemispheres. Heart: high interventricular septal defect. No other visceral abnormality. See Fig. 1.

Case 472. Karyotype 47,XY, +18 ; stillborn (macerated); gestation 39 weeks; weight at necropsy 1193 g. Multiple abnormalities; ears primitive, small and with only partial separation of the pinnae from the scalp. Microphthalmia, hypertelorism, microstomia, and micrognathia. Bilateral flexion deformities of fingers; dysplastic nails; no Simian creases. Exomphalos. 


\section{Chromosome studies in investigation of stillbirths and neonatal deaths}

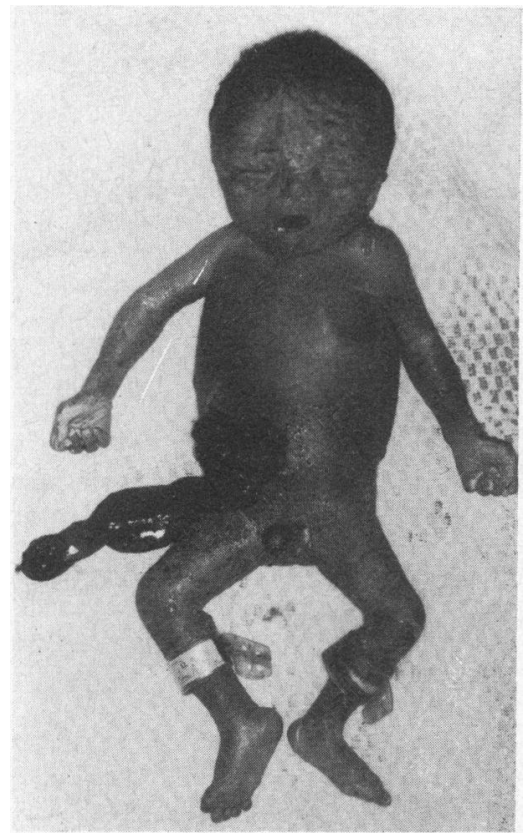

FIG. 2.-Case 472. Note maceration, flexion deformity of fingers, short great toes, small penis, grossly oedematous umbilical cord.

Normal placenta with grossly oedematous umbilical cord; single umbilical artery. Small penis; undescended testes. Oedematous legs. Brain normal. Heart enlarged with transposition of the great vessels and ventricular septal defect. Malrotation of the ileum and ascending colon; absent appendix. Meckel's diverticulum with ectopic pancreatic tissue at its tip. Left hydroureter with ureteric stenosis, right double ureter. See Fig. 2.

Case 351. Karyotype $47, \mathrm{XX},+18$; age $6 \frac{1}{2} \mathrm{hr}$; gestation 34 weeks; weight at necropsy $1395 \mathrm{~g}$. Multiple abnormalities; odd facies with large mandible; exomphalos; right talipes equinovarus ; partial syndactyly of 4th and 5th toes. Brain normal. Heart: ventricular septal defect. Single umbilical artery.

Case 387. Karyotype $47, \mathrm{XX},+18$; age $48 \mathrm{hr}$; gestation 38 weeks; weight at necropsy $1249 \mathrm{~g}$. Multiple external abnormalities. Odd facies. Nipples widely spaced. Exomphalos. Bilateral partial syndactyly of 3rd and 4th fingers. Flexion deformity of both thumbs, but no flexion deformity of other fingers. Bilateral single transverse palmar creases. Bilateral talipes with rocker-bottom feet; short great toes. Brain normal. Oesophageal atresia, jejunal stenosis. Heart: atrial septal defect; ventricular septal defect, mitral

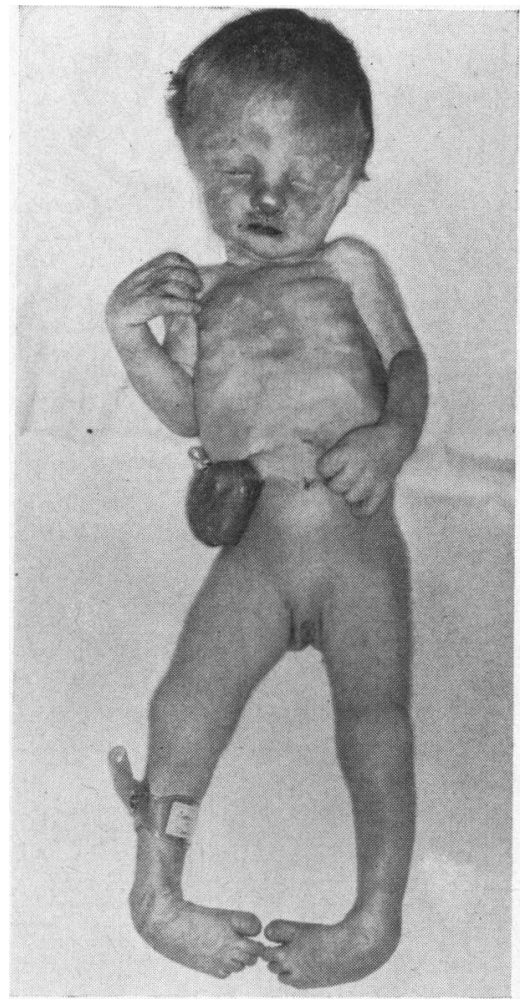

FIG. 3.-Case 387. Note exomphalos, talipes, short great toes.

atresia, widely persistent ductus arteriosus. Horseshoe kidney. Hypoplastic uterus; vesicovaginal fistula. See Fig. 3.

Case 419. Karyotype $47, \mathrm{XX},+18$; age $1 \frac{1}{2} \mathrm{hr}$; gestation 35 weeks; weight at necropsy $1020 \mathrm{~g}$. Twin pregnancy-other twin chromosomally normal. Multiple external abnormalities. Odd facies with micrognathia; ears flattened with the helix underdeveloped. Flexion deformities of fingers and bilateral single palmar creases. Rocker-bottom feet; short great toes. Exomphalos. Head: anterior falx defect with fusion of the cerebral hemispheres in this region. Oesophageal atresia. Heart: high interventricular septal defect. Meckel's diverticulum with ectopic pancreatic tissue at its tip. Kidneys normal.

Case 264. Karyotype 47,XXX; stillborn; gestation 31 weeks; weight at necropsy $1512 \mathrm{~g}$. No obvious external deformity. Brain and spinal cord showed normal developmental features consistent with 30-32 weeks' gestation. Lungs airless. Multiple petechial haemorrhages present over the visceral pleura and pericardium. Heart normal. No visceral or genital abnormality. Rhesus isoimmunization. 


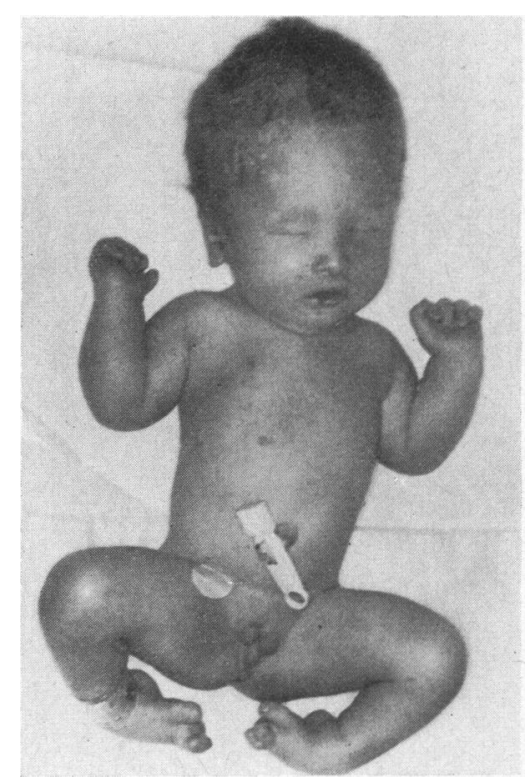

FIG. 4.-Case 479. Note anomalous genitalia, bilateral equinovarus deformity, large head.

Case 294. Karyotype $46, \mathrm{XY} / 47, \mathrm{XY},+\mathrm{C}$; abortion; gestation 27 weeks; weight at necropsy $1125 \mathrm{~g}$. No external deformities recognized. Brain and meninges: normal, developmental features consistent with 26 weeks' gestation. Multiple petechiae present over both lungs. Heart normal. No visceral abnormalities.

Case 461. Karyotype $46, \mathrm{XX} / 47, \mathrm{XX},+\mathrm{C}$; age $58 \mathrm{hr}$; gestation 32 weeks; weight at necropsy $1580 \mathrm{~g}$. Infant showed discoloured anterior abdominal wall. Epicanthic folds; micrognathia, low-set ears. Brain and meninges normal. Thoracic organs normal. Patchy infarction of the intestine from midileum distally. Large intestine severely affected. Liver extremely congested. Death due to enterocolitis.

Case 297. Karyotype 69,XXY; abortion; gestation 23 weeks; weight at necropsy $500 \mathrm{~g}$. Male fetus with no obvious external abnormality. Brain meninges and spinal cord normally developed for 20 weeks' gestation. Thoracic organs structurally normal. Right kidney showed cystic dysplasia and was 3 times normal size; left kidney normal. No other visceral abnormality. Placenta weighed $423 \mathrm{~g}$.

Case 479. Karyotype $46, X Y$, der $13, t(7 ; 13$ ) (q36; q22) pat.; age 6 days; gestation 39 weeks; weight at necropsy 2578 g. Anomalous external genitalia. Severe bilateral equinovarus with syndactyly of 4 th and 5th digits. Head was large; bilateral microphthalmia; cerebral holosphere with hydranencephalus. Spinal cord normal. All thoracic organs normal. No visceral abnormality except for hypoplastic kidneys. See Fig. 4. 